\title{
Pengaruh kompensasi finansial dan motivasi mengajar terhadap kinerja Guru SMK Wahid Hasyim Glagah
}

( Studi Kasus Pada SMK Wahid Hasyim Glagah )

\section{Darianto}

Institut Teknologi Dan Bisnis Ahmad Dahlan Lamongan

abuqarni10@gmail.com

\section{Siti Musarofah}

Institut Teknologi Dan Bisnis Ahmad Dahlan Lamongan

\section{Ayu Lestari}

Institut Teknologi Dan Bisnis Ahmad Dahlan Lamongan

\begin{abstract}
This study aims to examine and analyze the effect of financial compensation and teaching motivation on the performance of SK Wahid Hasyim Glagah teachers considering the importance of human resource potential in a school operating system. This research was conducted at the Wahid Hasyim Glagah vocational school, the sample used was 100\% of the number of teachers and used quantitative methods. The data were obtained statistically with the SPSS for windows 26.0 program. The results of the study simultaneously financial compensation and teaching motivation had a positive and significant effect on the performance of SMK Wahid Hasyim Glagah teachers. Partially, financial compensation and teaching motivation have a significant effect on the teacher's performance at SMK Wahid Hasyim Glagah.
\end{abstract}

Keywords financial compensation, teaching motivation, teacher performance.

\section{PENDAHULUAN}

Sekolah kejuruan merupakan salah satu upaya pemerintah untuk meningkatkan sumber daya manusia yang berkualitas serta memiliki keterampilan dan daya saing tinggi. Sekolah menegah kejuruan merupakan pendidikan menegah kejuruan yang mempersiapkan peserta didik untuk bekerja dalam bidang tertentu, dapat beradaptasi di lingkungan kerja, dapat melihat peluang kerja serta dapat megembangkan diri di kemudian hari agar menjadi tenaga kerja yang profesional.

Untuk menghasilkan siswa yang ahli dalam bidangnya dan yang siap bekerja sesuai dengan tuntutan dunia kerja maka diperlukan guru yang professional dan memiliki kinerja yang sangat baik dalam menjalankan tugas sesuai dengan profesinya sebagai seorang tenaga pendidik. Hasil pendidikan yang baik menjadi tolak ukur bagi keberhasilan kinerja yang ditunjukkan guru. Keberhasilan guru dalam menjalankan tugasnya dapat dilihat dari hasil belajar yang diperoleh oleh siswa yang di didikoleh guru tersebut. Salah satu alat yang dapat dijadikan ukuran untuk menilai keberhasilan siswa dalam belajar ialah nilai yang diperoleh oleh siswa dari setiap mata pelajaran yang diikutinya. Guru dikatakan berhasil mendidik ketika semua siswa yang di didiknya mendapatkan nilai yang sangat memuaskan dari pelajaran yang diampunya. Jika nilai semua siswa yang di didik oleh guru dari mata pelajaran yang diampunya memperoleh 
nilai yang sangat memuaskan maka dapat dikatakan guru tersebut memiliki kinerja yang sangat baik.

Kinerja guru dapat dilihat dan diukur berdasarkan spesifikasi/kriteria kompentensi yang harus dimiliki oleh setiap guru. Berdasarkan Peraturan Menteri Pendidikan Nasional Republik Indonesia Nomor 16 Tahun 2007 tentang Standar Kualifikasi Akademik dan Kompetensi Guru, dijelakan bahwa Standar Kompetensi Guru dikembangkan secara utuh dari 4 kompetensi utama, yaitu: (1) kompetensi pedagogik, (2) kepribadian, (3) sosial, (4) profesional. Keempat kompetensi tersebut terintegrasi dalam kinerja guru (Permendiknas, 2007:18). Kinerja guru dikatakan baik jika guru telah melakukan unsur-unsur yang terdiri dari kesetiaan dan komitmen yang tinggi pada tugas mengajar, menguasai materi pelajaran secara luas disiplin ilmu yang diajarkan kepada peserta didik, mengembangkan bahan pelajaran, kreativitas dalam pelaksanaan pengajaran, kerjasama dengan semua warga sekolah, kepimpinan yang menjadi penutan peserta didik, kepribadian yang mantap, berakhlak mulia, arif dan berwibawa, jujur, objektif dalam membimbing peserta didik, dan tanggung jawab terhadap tugasnya. Guru sebagai masyarakat sosial harus mampu berinteraksi dengan efektif dan efisien kepada peserta didik, sesama guru, orang tua, dan masyarakat luas. Kinerja guru sangat menentukan keberhasilan proses belajar yang efektif dan efisien sehingga tujuan pendidikan dapat tercapai dan terwujud dari hasil belajar peserta didik yang baik. Hasil belajar peserta didik yang baik dapat mencetak lulusan yang berkualitas. Guru sebagai ujung tenaga pelaksana pendidikan hendaknya memiliki kinerja yang baik dan berkwalitas, sehingga diharpkan tujuan dari pendidikan dapat tercapai dengan optimal.

\section{LANDASAN TEORI \\ Kompensasi Finansial}

Kompensasi adalah sesuatu yang diterima para karyawan sebagai balas jasa atas prestasinya dalam melaksanakan tugas. Kompensasi diberikan kepada setiap karyawan yang telah bekerja dalam suatu perusahaan sebagai timbal balik atas pekerjaan yang telah dilakukan oleh karyawan tersebut. Tingkat kompensasi yang diberikan dapat mempengaruhi kinerja karyawan dalam meningkatkan produktivitas.

Semakin tinggi kompensasi yang diberikan kepada karyawan akan termotivasi untuk melakukan pekerjaanya dengan lebih baik lagi. Jika kompensasi yang diberikan rendah, kinerja karyawan akan menurun karena karyawan merasa kompensasi yang diberikan tidak sesuai dengan beban pekerjaanya.

\section{Motivasi Mengajar}

Motivasi merupakan suatu alasan agar orang (bawahan) mau bekerja keras dan bekerja cerdas sesuai dengan apa yang diharapkan (Husaini, 2010: 249). Schermerhorn, dalam Winardi (2004: 2) menyatakan bahwa motivasi untuk bekerja merupakan sebuah istilah yang digunakan untuk menerangkan kekuatan-kekuatan yang terdapat pada diri seorang individu, yang menjadi sebab timbulnya tingkat arah, dan persistensi upaya yang dilaksanakan dalam hal bekerja.

Sementara itu, Luthans (2008) berpendapat bahwa motivasi adalah suatu proses yang dimulai dengan kekurangan kegiatan kehidupan atau kebutuhan jiwa atau kebutuhan yang mengaktifkan perilaku/tekad yangmengarah pada suatu tujuan atau dorongan. Dengan demikian, maka motivasi mengajar guru adalah serangkaian daya penggerak yang adapada guru yang menjadi menjadi sebab timbulnya tingkat, arah, dan 
persistensi upaya yang dilaksanakan dalam hal mengajar yang dapat dilihat dari; 1) prestasi; 2) pengakuan; 3) pekerjaan itu sendiri, dan; 4) tanggung jawab.

\section{Kinerja Guru}

Kinerja guru adalah hasil kerja guru yang terefleksi dalam cara merencanakan, melaksanakan dan menilai proses belajar mengajar yang intensitasnya dilandasi oleh etos kerja, serta disiplin profesional dalam proses pembelajaran (Uno, 2014: 86). Menurut Sudarmi (2013:45-47) mendefinisikan "kinerja merupakan suatu kegiatan yang dilakukan untuk melaksanakan, menyelesaikan tugas dan tanggung jawab sesuai dengan harapan dan tujuan yang telah ditetapkan". Kinerja mengandung makna hasil kerja, kemampuan, prestasi atau dorongan untuk melaksanakan suatu pekerjaan.

Kinerja guru dapat ditunjukkan dari kemampuan guru dalam menguasai kompetensi yang dipersyaratkan, yakni kompetensi pedagogik, kompetensi kepribadian, kompetensi sosial, dan kompetensi profesional (Undang-Undang Nomor 14 Tahun 2005). Menurut Hadiyanto dan Subiyanto (2003: 8) dijelaskan bahwa iklim pembelajaran yang kondusif antara lain dapat mendukung: (1) interaksi yang bermanfaat di antara peserta didik, (2) memperjelas pengalaman- pengalaman guru dan peserta didik, (3) menumbuhkan semangat yang memungkinkan kegiatan-kegiatan di kelas berlangsung dengan baik, dan (4) mendukung saling pengertian antara guru dan peserta didik.

\section{METODOLOGI PENELITIAN}

Penelitian ini menggunakan jenis penelitian kuantitatif. Jenis penelitian kuantitatif adalah metode yang digunakan untuk penyajian hasil penelitian dalam bentuk angka-angka atau statistik, jenis penelitian kuantitatif digunakan untuk menguji hipotesis. Penelitian ini dimaksudkan untuk mendapatkan informasi langsung tentang masalah yang dibahas pada tugas akhir ini dengan variabel kompensasi finansial (X1) motivasi mengajar (X2) terhadap kinerja guru (Y).

Dalam penelitian ini yang menjadi populasi dalam penelitian ini adalah guru SMK Wahid Hasyim Glagah Lamongan, sejumlah 37 orang dengan mengunakan teknik total sampling. Sumber data yang digunakan dalam penelitian ini adalah data primer dan data sekunder. Metode pengumpulan data menggunakan Kuisioner/angket observasi, wawancara/interview dan studi kepustakaan.

\section{HASIL PENELITIAN}

\section{Uji Validitas}

Berikut adalah hasil dari pengujian validitas data penelitian :

Tabel 1. Hasil Uji Validitas

\begin{tabular}{|c|c|c|c|}
\hline Variabel & $\mathrm{r}_{\text {hitung }}$ & $\mathrm{r}_{\text {tabel }}$ & $\begin{array}{c}\text { Interpre } \\
\text { tasi }\end{array}$ \\
\hline Kompensasi Finansial & & & \\
1 & 0,880 & 0,325 & Valid \\
2 & 0,750 & 0,325 & Valid \\
3 & 0,319 & 0,325 & Valid \\
4 & 0,558 & 0,325 & Valid \\
5 & 0,564 & 0,325 & Valid \\
6 & 0,382 & 0,325 & Valid \\
\hline
\end{tabular}




\begin{tabular}{|c|c|c|c|}
\hline \hline 7 & 0,677 & 0,325 & Valid \\
& 0,550 & 0,325 & Valid \\
\hline Motivasi Kerja & & & \\
1 & 0,374 & 0,325 & Valid \\
2 & 0,531 & 0,325 & Valid \\
3 & 0,557 & 0,325 & Valid \\
4 & 0,666 & 0,325 & Valid \\
5 & 0,444 & 0,325 & Valid \\
6 & 0,363 & 0,325 & Valid \\
7 & 0,442 & 0,325 & Valid \\
Kinerja Guru & 0,334 & 0,325 & Valid \\
1 & & & \\
2 & 0,502 & 0,325 & Valid \\
3 & 0,399 & 0,325 & Valid \\
4 & 0,403 & 0,325 & Valid \\
5 & 0,494 & 0,325 & Valid \\
6 & 0,404 & 0,325 & Valid \\
7 & 0,665 & 0,325 & Valid \\
8 & 0,491 & 0,325 & Valid \\
\hline
\end{tabular}

Berdasarkan pengujian pada tabel validitas, diketahui bahwa $r$ hitung lebih besar dari $r$ tabel. Oleh karena itu dapat disimpulkan kesimpulan bahwa secara keseluruhan data dinyatakan valid.

\section{Uji Reliabilitas}

Hasil uji reliabilitas dengan menggunakan SPSS 26, sebagai berikut:

Tabel 2 Hasil Uji Reliabilitas

\begin{tabular}{|l|c|c|}
\hline \multicolumn{1}{|c|}{ Variabel } & $\begin{array}{c}\text { Koefisien } \\
\text { Alpha }\end{array}$ & Interpretasi \\
\hline \hline Kompensasi Finansial & 0,730 & Reliabel \\
\hline Motivasi Kerja & 0,616 & Reliabel \\
\hline Kinerja Guru & 0,718 & Reliabel \\
\hline
\end{tabular}

Berdasarkan pengujian pada tabel uji reliabilitas diatas, diketahui bahwa masing-masing variabel memiliki nilai Croanbach's Alpha lebih besar dari 0,60. Oleh karena itu dapat disimpulkan jika item pertanyaan variabel adalah reliabel.

\section{Uji Normalitas}

Berikut ini adalah hasil uji normalitas : 


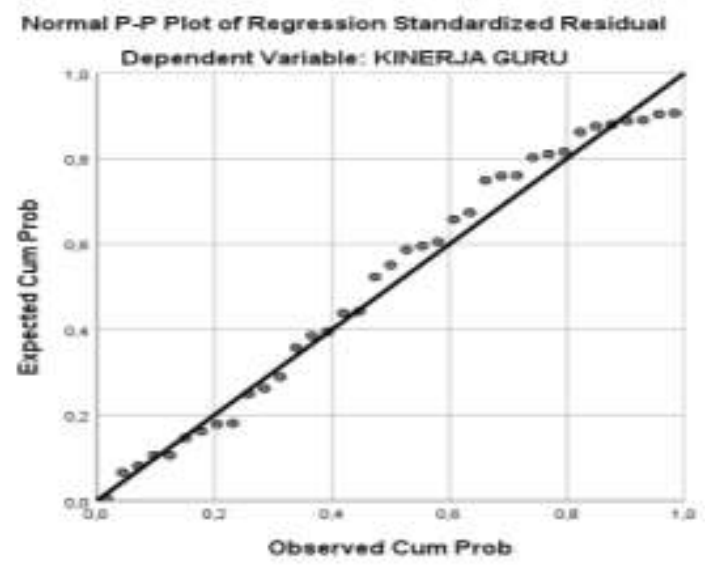

Gambar 1

Hasil Uji Normalitas

Dapat diketahui bahwa titik penyebaran data berada pada sekitar sumbu diagonal dan mengikuti arah garis diagonal, maka dapat disimpulkan data berdistribusi secara normal.

\section{Uji Multikolinieritas}

Hasil hasil uji multikolinieritas berikut ini :

Tabel 3

Hasil Uji Multikolinieritas

\begin{tabular}{|l|c|c|}
\hline \multicolumn{1}{|c|}{ Variabel } & Tolerance & VIF \\
\hline $\begin{array}{l}\text { Kompensasi } \\
\text { Finansial }\end{array}$ & 0,873 & 1,146 \\
\hline Motivasi Kerja & 0,873 & 1,146 \\
\hline
\end{tabular}

Berdasarkan pengujian pada table multikolinieritas dapat disimpulkan bahwa tidak terjadi gejala multikolinieritas atau bebas multikolonieritas.

\section{Uji Heteroskedastisitas}

Hasil dari uji heteroskedastisitas berikut ini :

\section{Tabel 4}

Hasil Uji Heteroskedastisitas

\begin{tabular}{|l|c|c|l|}
\hline Variabel & Signifikansi & Alpha & Keterangan \\
\hline $\begin{array}{l}\text { Kompensasi } \\
\text { Finansial }\end{array}$ & 0,948 & 0,05 & $\begin{array}{l}\text { Bebas } \\
\text { heteroskedastisitas }\end{array}$ \\
\hline $\begin{array}{l}\text { Motivasi } \\
\text { Kerja }\end{array}$ & 0,122 & 0,05 & $\begin{array}{l}\text { Bebas } \\
\text { heteroskedastisitas }\end{array}$ \\
\hline
\end{tabular}

Pada tabel heteroskedastisitas diatas terdapat nilai signifikansi kompensasi finansial sebesar 0,948>0,05. Dapat disimpulkan bahwa tidak terdapat gejala heteroskedastisitas atau bebasheteroskedastisitas. Sedangkan nilai signifikansi motivasi mengajar sebesar $0,122<0,05$. Dapat diartikan bahwa tidak terdapat gejala heteroskedastisitas atau bebas heteroskedastisitas. 


\section{Analisis Regresi Linier Berganda}

Hasil Analisis Regresi Linier Berganda sebagai berikut:

\section{Table 5}

\section{Coefficients $^{\mathrm{a}}$}

\section{Hasil Uji Analisis Regresi Linier Berganda}

\begin{tabular}{|c|c|c|c|c|c|c|c|c|}
\hline \multirow{2}{*}{ Model } & & \multicolumn{2}{|c|}{$\begin{array}{l}\text { Unstandardized } \\
\text { Coefficients }\end{array}$} & \multirow{2}{*}{$\begin{array}{l}\text { Standardized } \\
\text { Coefficients } \\
\text { Beta }\end{array}$} & \multirow[b]{2}{*}{$\mathrm{t}$} & \multirow[b]{2}{*}{ Sig. } & \multicolumn{2}{|c|}{ Collinearity Statistics } \\
\hline & & B & $\begin{array}{l}\text { Std. } \\
\text { Error }\end{array}$ & & & & Tolerance & VIF \\
\hline \multirow[t]{3}{*}{1} & (Constant) & 4,482 & 3,063 & & 1,463 & ,153 & & \\
\hline & $\begin{array}{l}\text { KOMPENSASI } \\
\text { FINANSIAL }\end{array}$ & ,754 &, 141 & ,766 & 5,354 &, 000 & ,539 & 1,855 \\
\hline & $\begin{array}{l}\text { MOTIVASI } \\
\text { MENGAJAR }\end{array}$ &, 041 &, 165 &, 035 &, 247 &, 806 & 539 & 1,855 \\
\hline
\end{tabular}

a. Dependent Variable: KINERJA GURU

Berdasarkan perhitungan yang dilakukan menggunakan SPSS 26 akan di dapatkan persamaan regresi linier berganda dengan hasil sebagai berikut :

1. Nilai variabel dependen kinerja guru (Y) dapat dilihat dari nilai konstantanya sebesar 4,482 dengan catatan jika variabel independen kompensasi finansial dan motivasi mengajar.

2. Diketahui coefficient regresi dari tingkat kompensasi finansial sebesar 0,754 . Tanda tersebut positive yang artinya ada hubungan yang searah. Dapat diartikan bahwa peningkatan $1 \%$ kompensasi finansial akan menyebabkan peningkatan kinerja guru sebesar 0,754 .

3. Diketahui coefficient regresi dari tingkat motivasi mengajar sebesar 0,041 . Tanda tersebut positive yang artinya ada hubungan yang searah. Dapat diartikan bahwa peningkatan $1 \%$ motivasi mengajar akan menyebabkan peningkatan kinerja guru sebesar 0,041 .

4.

\section{Uji Signifikasi Parsial (Uji t)}

Hasil Uji t dapat dilihat pada tabel sebagai berikut:

\section{Tabel 6}

Hasil Uji Signifikasi Parsial (Uji t)

\begin{tabular}{|l|c|c|l|}
\hline \multicolumn{1}{|c|}{ Variabel } & $\mathrm{t}_{\text {hitung }}$ & Signifikansi & Keterangan \\
\hline $\begin{array}{l}\text { Kompensasi } \\
\text { Finansial }\end{array}$ & 7,624 & 0,000 & Signifikan \\
\hline $\begin{array}{l}\text { Motivasi } \\
\text { Kerja }\end{array}$ & 3,952 & 0,000 & Signifikan \\
\hline
\end{tabular}

Berikut mengenai pengaruh masing-masing variabel independen secara parsial :

1. Pengaruh kompensasi finansial terhadap kinerja guru nilai dari t hitung kompensasi finansial sebesar 7,624 dengan nilai signifikansi $0,000<0,05$ maka kompensasi finansial berpengaruh signifikan terhadap kinerja guru.

2. Pengaruh motivasi mengajar terhadap kinerja guru nilai dari t hitung motivasi mengajar sebesar 3,952 dengan nilai signifikansi $0,000<0,05$ maka motivasi mengajar berpengaruh signifikan terhadap kinerja guru. 


\section{Uji Signifikasi Simultan (Uji F)}

Table 7

\begin{tabular}{|c|c|}
\multicolumn{2}{|c}{ Hasil Uji $\mathbf{~}$} \\
\hline F & Sig. \\
\hline 38,311 & 0,000 \\
\hline
\end{tabular}

Dari olah data di atas dapat diketahui bahwa nilai $\mathrm{F}$ hitung sebesar 38,311 dan nilai signifikansi $0,000<0,05$ maka dapat disimpulkan kompensasi finansial dan motivasi mengajar berpengaruh secara simultan terhadap kinerja guru.

\section{Pembahasan Hasil Penelitian}

\section{Pengaruh Kompensasi Finansial terhadap Kinerja Guru}

Berdasarkan hasil analisis regresi dapat dinyatakan bahwa kompensasi finansial berpengaruh terhadap kinerja guru SMK Wahid Hasyim Glagah. Jika kompensasi finansial tinggi maka kinerja guru akan meningkat. Jika kompensasi finansial rendah maka kinerja guru akan turun.

Hasil penelitian ini sejalan dengan penelitian terdahulu yang dilakukan oleh Roslena Septiana (2013), Nuraini Firmandari (2014), Trisni Handayani (2015), Titik Handayani (2015) dan Muhammad Iqbal Baihaqi (2015). Dari hasil penelitian yang dilakukan penelitian tersebut menunjukkan hasil kompensasi finansial berpengaruh terhadap kinerja guru. Jadi semakin tinggi kompensasi finansial akan meningkatkan kinerja guru.

\section{Pengaruh Motivasi Mengajar terhadap Kinerja Guru}

Berdasarkan hasil analisi regresi dapat dinyatakan bahwa motivasi mengajar berpengaruh terhadap kinerja guru SMK Wahid Haysim Glagah. Jika motivasi mengajar mendukung maka kinerja guru akan meningkat. Jika motivasi mengajar tidak mendukung maka kinerja guru akan menurun.

Penelitian ini sejalan dengan penelitian terdahulu yang dilakukan oleh Muhammad Iqbal Baihaqi (2015), Luis Aparicio Guterres (2016), Reza Ahmadiansah (2016), Yesmira Syamra (2016) dan Bayu Hendro Priyono (2018). Dari hasil penelitian tersebut menunjukan hasil bahwa motivasi mengajar berpengaruh terhadap kinerja guru. Motivasi mengajar yang mendukung akan meningkatkan kinerja guru.

\section{Implikasi Hasil Penelitian}

\section{Implikasi Teoritis \& Praktis}

1. Untuk membuktikan hasil penelitian ini mengenai pengaruh kompensasi finansial dan motivasi mengajar terhadap kinerja guru. Dari hasil penelitian tersebut dapat mengembangkan ilmu pengetahuan di bidang sumber daya manusia serta menjadi referensi untuk dikaji ulang mengenai kompensasi finansial, motivasi mengajar berpengaruh terhadap kinerja guru.

2. Bagi pihak-pihak yang berkepentingan dalam hasil penelitian, harapam penulis dapat berkontribusi meningkatkan sumber daya manusia dengan meningkatkan kompensasi finansial serta motivasi mengajar untuk menghasilkan peningkatan kinerja guru.

3. Untuk peneliti selanjutnya, untuk menjadi salah satu referensi dalam mengembangkan penelitian selanjutnya mengenai kompensasi finansial dan motivasi mengajar. Alangkah lebih baik menambahkan variabel independen yang 
lebih dari penelitian ini sehingga dapat mengetahui variabel yang dominan terhadap peningkatan kinerja guru.

\section{KESIMPULAN}

Berdasarkan hasil penelitian yang dilakukan, maka kesimpulan yang dapat dikemukakan dalam penelitian ini adalah sebagai berikut :

1. Kompensasi finansial secara parsial berpengaruh positif dan signifikan terhadap kinerja guru SMK Wahid Hasyim Glagah. Jadi, jika sekolah memberikan kompensasi finansial yang sesuai dengan apa yang sudah dikerjakan guru untuk sekolah maka hal tersebut akan meningkatkan kinerja guru.

2. Motivasi mengajar secara parsial berpengaruh positif dan signifikan terhadap kinerja guru SMK Wahid Hasyim Glagah. Jadi, jika guru SMK Wahid Hasyim Glagah memiliki motivasi kerja dalam dirinya maka hal tersebut akan mendorong guru SMK Wahid Hasyim Glagah melakukan pekerjaannya dengan baik sehingga kinerja guru akan meningkat.

3. Kompensasi finansial dan motivasi mengajar secara simultan berpengaruh positif dan signifikan terhadap kinerja guru SMK Wahid Hasyim Glagah. Kompensasi finansial dan motivasi mengajar merupakan unsur penting dalam upaya meningkakan kinerja guru. Jadi, semakin tinggi motivasi kerja guru didukung dengan kompensasi finansial yang diberikan sekolah maka akan mendorong guru SMK Wahid Hasyim Glagah untuk melakukan kinerja yang lebih baik.

\section{DAFTAR PUSTAKA}

AA. Anwar Prabu Mangkunegara. 2013. Manajemen Sumber Daya Manusia Perusahaan, Remaja Rosdakarya, Bandung.

Afifah, Marnesya. 2011. Pengaruh Motivasi, Kompensasi Dan Pengembangan Karir Terhadap Kinerja Guru (Studi Kasus Pada SMK Nusantara Jl. Tarumanegara dalam No 1 Ciputat). Skripsi Manajemen Universitas Islam Negeri Syarif Hidayatullah Jakarta.

Ahmadi. Edy Anas, Herwidyaningtyas, Fristina Bhakti, Fatimah. Siti. 2020. The Influence Of Organizational Culture, Work Motivation, And Job Satisfaction On Management Lecturer Performance (Empirical Study At Higher Education In The Residency Of Bojonegoro. Journal Of Industrial Engineering \& Management Research. Jilid 1. Terbitan 3 Halaman 76-83Bangun, Wilson. 2012. "Manajemen Sumber Daya Manusia". Jakarta: Erlangga.

Bayu, Hendro Priyono. (2018). Pengaruh Gaya Kepemimpinan, Motivasi Guru Dan Lingkungan Kerja Fisik Terhadap Kinerja Guru SMAN 1 Tanggul Jember. Jurnal Manajemen dan Bisnis Indonesia Vol 4 No 2.

Dessler, Gary. 2011. Manajemen Sumber Daya Manusia. Penerbit Indeks, Jakarta.

Engky, Karweti. (2010). Pengaruh Kemampuan Manajerial Kepala Sekolah Dan F aktor Yang Mempengaruhi Motivasi Kerja Terhadap Kinerja Guru SLB Di Kabupaten Subang. Jurnal Penelitian Pendidikan Vol. 11 No.2

Gilang, Ramadan. (2018). Pengaruh Gaya Mengajar Dan Motivasi Belajar Terhadap Hasil Belajar Lay Up Shoot (Studi Pada SMA Negeri 1 Cigugur). JPE (Jurnal Pendidikan Edutama) Vol 5 No 1.

Hasibuan, Malayu. 2005. Organisasi dan Motivasi : dasar peningkatan produktivitas. Jakarta: Bumi Aksara. 
Hasibuan, Malayu. 2016. Manajemen Sumber Daya Manusia. Jakarta: Penerbit Bumi Aksara.

Husein, Umar. 2005. Riset Sumber Daya Manusia Dalam Organisasi. Edisi Revisi. Jakarta: PT. Gramedia Pustaka Utama.

Kus, Daru Widayati. (2019). Pengaruh Kompensasi Terhadap Kinerja Guru Pada Sekolah dasar Negeri Jatiwaringin X Bekasi. Volume 3 No 1.

Luis, Aparicio Guterres. (2016). Pengaruh Gaya Kepemimpinan Dan Motivasi Kerja Terhadap Kinerja Guru (Studi Pada SMU Negeri 2 Baucau Timor Leste). EJurnal Ekonomi dan Bisnis Universitas Udayana 5.3.

Luthans, Fed. (2008) Organizztional Behavior.McGraw-Hill Campanies,Inc.New York.

Mangkunegara, DR. A.A. Anwar Prabu. 2005. Evaluasi Kinerja SDM. Bandung: Refika.

M Purba, D Simanjutak, Y Malau, W Sholihat, E Ahmadi. 2021. The Effect Of Digital Marketing And E-Commerce On Financial Performance And Business SustainaBility Of Msmes During Covid-19 Pandemic In Indonesia. International Journal Of Data And Network Science. Jilid 5. Terbitan 3. Halaman 275-282

Mokhamad, Yanuar Pradita. (2017). Pengaruh Kompensasi, Gaya Kepemimpinan Dan Karakteristik Tenaga Pemasar Terhadap Motivasi Dan Kinerja Tenaga Pemasaran Pada PT. Bank Rakyat Indonesia (PERSERO) Tbk. Cabang Jombang. Jurnal Bisnis dan Manajemen Vol 4 No 2.

Muhammad, Iqbal Baihaqi. (2015). Pengaruh Gaya Kepemimpinan Kepala Sekolah Dan Motivasi Kerja Terhadap Kinerja Guru Di MA Ma'arif Selorejo Blitar. Konstruktivisme, Vol 7 No 2.

Nuraini, Firmandari. (2014). Pengaruh Kompensasi Terhadap Kinerja Karyawan Dengan Motivasi Kerja Sebagai Variabel Moderasi (Studi Pada Bank Syariah Mandiri Kantor Cabang Yogyakarta). Jurnal Ekonomi dan Bisnis Islam Vol. IX, No. 1.

Nurjaman, Kadar. 2014. Manajemen Personalia. Bandung : CV Pustaka Setia.

Priansa, D. J. (2016). Perencanaan \& Pengembangan SDM. Bandung: Alfabeta.

Reza, Ahmadiansah. (2016). Pengaruh Motivasi Kerja Dan Kepuasan Kerja Terhadap Kinerja Guru SMK Muhammadiyah Salatiga. Inject, Interdisciplinary Journal Of Communication, Vol 1 No 2.

Roslena, Septiana. (2013). Pengaruh Kepemimpinan Kepala Sekolah Dan Motivasi Kerja Terhadap Kinerja Guru SMP Negeri Wonosari. Jupe UNS, Vol 2 No 1 Hal $107 \mathrm{~s} / \mathrm{d} 118$

Samson, Danny, dan Daft, Richard L. 2012. Management. Cengage Learning. 